\title{
USING IMPROVISATION TO DEVELOP LEADERSHIP FOR A
} VOLATILE WORLD

\section{Abstract}

Many scholars have noted the critical skills needed for leaders in the face of volatility, uncertainty, complexity, and ambiguity (VUCA). These skills include self-awareness, listening, communication, adaptability, critical thinking, and collaboration. Students who are able to develop these skills would be better equipped to lead in settings where the answers-and even the questions-are unknown. This paper details an approach to developing leadership skills to prepare undergraduate leadership students for a VUCA world, through the use of a classroom workshop on improvisational comedy. I have refined this improv workshop over sixteen course iterations spanning the past nine semesters, and students commonly point to the workshop as one of the most challenging and rewarding class sessions of the course. In this paper I review the literature that has informed my approach, explain the learning objectives addressed by the improv workshop, describe the approach I use, share quantitative and qualitative data that illustrate the success of the approach, and share my lessons learned, all in service of supporting colleagues who wish to try this approach.

"That contemporary organizations face high levels of complexity, a rapid rate of change and increased ambiguity has become, perhaps, a truism."

\section{Issue Statement}

As nicely captured in the quote above from Gagnon, Vough, and Nickerson (2012, p. 300), it is a taken-forgranted assumption that organizational life is marked by what the United States Army calls VUCA: volatility, uncertainty, complexity, and ambiguity (Gerras, 2010). Every generation can reasonably claim theirs is the most VUCA yet, stretching back even before the advent of the printing press, the steam engine, radio communication, and other transformational technologies. Today is no different; we live in the most VUCA world (so far), and we must equip students with the tools they need to lead in this world.

Many scholars have noted the critical skills needed for leaders in the face of volatility, uncertainty, complexity, and ambiguity. These skills include selfawareness, listening, communication, adaptability, critical thinking, and collaboration (Chikeleze, Johnson, \& Gibson, 2018; Colbry, Hurwitz, \& Adair, 2014; Guenthner \& Moore, 2005; Lindsay, Hassan, \& Day, 2009; Oberg \& Andenoro, 2019). Students who are able to develop these skills would be better equipped to lead in settings where the answers-and even the questions-are unknown, since they will be able to test their assumptions and tap into the collective abilities of those around them.

The present paper details an approach to developing leadership skills to prepare undergraduate leadership 
students for a VUCA world, through the use of a classroom workshop on improvisational comedy. I have refined this improv workshop over sixteen course iterations spanning the past nine semesters, and students commonly point to the workshop as one of the most challenging and rewarding class sessions of the course. In the following pages I review the literature that has informed my approach, explain the learning objectives addressed by the improv workshop, describe the method I use, share quantitative and qualitative data that illustrate the success of the approach, and share my lessons learned, all in service of supporting colleagues who wish to try this approach.

\section{Literature Review}

Twenty-five years have passed since the "Jazz Improvisation as a Metaphor for Organization Theory" symposium at the annual Academy of Management meeting that brought improvisation in organizations into the mainstream. Subsequent to the symposium, a special issue of Organization Science (Lewin, 1998) both coalesced previous work on improvisation and launched a stream of scholarship into organizational improvisation that continues through today. While many early scholars explored the metaphor of jazz improvisation (Barrett, 1998; Newton, 2004; Peplowski, 1998; Weick, 1998), subsequent research considered improvisational theater (April, Beall, \& Peters, 2015; Crossan, 1998; Gagnon, Vough, \& Nickerson, 2012; Gibb, 2004; Tawadros, 2015; Vera \& Crossan, 2005) and other contexts such as military missions, music therapy, and design thinking (Christopoulos, Wilner, \& Bestetti, 2016; Kamoche, Cunha, \& Cunha, 2003; Vera \& Rodriguez-Lopez, 2007). Interest in the phenomenon shows no sign of abating; as Fisher and Barrett (2019, p. 149) note, "Interest in organizational improvisation has grown over the past two decades."

Improvisation entails "the creative and spontaneous process of trying to achieve an objective in a new way" (Vera \& Crossan, 2005, p. 205), and it is especially valuable when faced with a novel, uncertain situation where no clear path forward exists (Barrett, 1998; Hadida, Tarvainen, \& Rose, 2015). If improvisation is a useful way to face a VUCA environment, it is no surprise interest in improvisation in organizations has grown over the past two decades. In the special issue of Organization Science devoted to improvisation, Weick (1998) described the world back then as being marked by "discontinuity, multiple commitments, interruptions, and transient purposes that dissolve without warning" (p. 551); this sounds very much like VUCA. It is safe to say that the world has become even more VUCA over the past twenty-odd years (Gagnon, Vough, \& Nickerson, 2012; Gerras, 2010), thereby increasing the need for leaders to learn how to improvise effectively.

I am, of course, not the first leadership instructor to use interactive experiential learning or improvisation to help students develop leadership skills. Authors have described, for example, their use of classroom debates (Chikeleze, Johnson, \& Gibson, 2018) and role-playing (Guenthner \& Moore, 2005; Tabak \& Lebron, 2017) to develop interpersonal, communication, and critical thinking skills. Regarding improvisation, several authors have detailed their use of improvisational theater to, for example, improve classroom climate (Huffaker \& West, 2005; Moshavi, 2001), develop presentation skills (Greenberg, 1995), improve case discussion (Aylesworth, 2008), or develop students' emotional intelligence (Shivarajan \& Andrews, 2019). Several others have employed improvisational theater in organizational training and development (April, Beall, \& Peters, 2015; Christopoulos, Wilner, \& Bestetti, 2016; Gagnon, Vough, \& Nickerson, 2012; Ratten, \& Hodge, 2016; Tawadros, 2015). Whereas the early scholarship in organizational improvisation focused on jazz improvisation, the use of improvisational theater welcomes all participants- even those 
without musical skills - and allows participants to improve communication and team skills readily transferable in their daily lives (Aylesworth, 2008; Crossan, 1998; Fisher \& Barrett, 2019; Vera \& Crossan, 2005). The hallmark of improvisational theater is the collaborative development of an unscripted scene or a story in the moment, using minimal inputs.

What is distinctive about my approach is the centrality of the improvisational skills in the leadership course, the unique partnership I have formed with the student improv club to deliver the workshop, and the data I have collected to provide evidence of the workshop's effectiveness. I will highlight these aspects in the sections that follow.

\section{Learning Objectives Addressed by Improvisation Workshop}

The course in which I have employed the improv workshop is an undergraduate leadership course, populated primarily by juniors and seniors fulfilling an elective. The minority of the students are enrolled in the undergraduate leadership major or minor. The course is designed to teach students leadership theory and skills, with about half of the course meetings devoted to covering essential leadership theories and the other half devoted to leadership skill development. The key leadership skills addressed are self-awareness, emotional intelligence, perspectivetaking, learning conversations, and conflict management. Similar to other leadership educators (Oberg \& Andenoro, 2019; Raymer, Dobbs, Kelley, \& Lindsay, 2018), I cover these topics in an iterative fashion, since developing greater self-awareness leads to greater emotional intelligence, which then leads to more effective perspective-taking, and so on. By the time we get to conflict management, then, we have spent several sessions developing and practicing self-awareness and affective- and cognitive-perspective-taking.

The improv workshop is an integrative experience, allowing students to practice seeing how the key intrapersonal (i.e., self-awareness) and interpersonal skills fit together. The workshop's objectives are to:
- Develop greater self-awareness by experiencing an unfamiliar and uncomfortable setting

- Develop stronger speaking skills

- Develop stronger listening skills

- Develop stronger collaboration skills

Improv is a natural way to address these learning objectives in one integrative experience. At the heart of practicing improvisation is being present to others, listening deeply to them with the intent to understand, contributing one's perspective to build the scene/conversation, and focusing more on what is good for the collective than what is only good for oneself. In addition to describing improvisation, the previous sentence might also describe the heart of what makes leaders effective with others-especially in the face of uncertainty (Gagnon, Vough, \& Nickerson, 2012).

Several scholars have noted how training in improvisation can develop intrapersonal skills such as self-awareness, self-confidence, creativity, adapting to the environment, forgiveness of mistakes, and being present to others (Aylesworth, 2008; Fisher \& Barrett, 2019; Gagnon, Vough, \& Nickerson, 2012; Huffaker \& West 2005; Koppett, 2002; Moshavi, 2001; Ratten \& Hodge, 2015). To build a scene with others, improvisers need to turn off their inner voices and listen to others. Otherwise, they won't know how the scene has shifted by the time their turn comes. They need also to recognize their discomfort, quickly forgive themselves and others when they make mistakes, and subjugate their interests to those of the group.

Researchers have also advocated for how improvisation training can develop key interpersonal skills needed by leaders and managers in a complex environment. These skills include listening, collaboration, empathy, perspective-taking, perspective-sharing, supporting others, and building psychological safety (April, Beall, \& Peters, 2015; Crossan, 1998; Gagnon, Vough, \& Nickerson, 2012; Huffaker \& West 2005; Koppett, 2002; Moshavi, 2001; 
Newton, 2004; Shivarajan \& Andrews, 2019). Essential to developing these skills through improvisation is to understand and practice the core improv approach of "Yes, and," which is found in virtually all schools of improvisational theater and comedy. To "yes, and" means one is accepting what is offered by another and then building upon that with their own offer. So if a participant says, "Hey, I'm heading to the store; do you want to come?" the other might say, "Sure thing, and on the way back we can stop at the groomers and pick up my llama." Embedded in the practice of "yes, and" is a bundle of interpersonal skills that serve leaders well in VUCA contexts, since it's only possible if one is listening deeply to the other and is committed to finding a collaborative and creative way to move forward.

\section{Using Improv Comedy in an}

\section{Undergraduate Leadership Class}

While some have used improv as a way to break the ice at the start of the semester (Huffaker \& West, 2005), I opt to conduct the improv workshop in my undergraduate leadership course at about a midpoint of the semester. My reasoning is twofold. First, this allows us to discuss and practice the foundational leadership skills presented above (i.e., self-awareness, perspective-taking, and conflict management) before integrating them with this workshop. Second, this allows us to get to know each other and begin building a level of psychological safety, thereby welcoming everyone to step into the discomfort of improv together (Greenberg, 1995).

Before the 75-minute class designated for the improv workshop, I assign articles describing the improvisational process and its application to a business context. While there are plenty of freelyavailable articles, the ones I prefer are Flanagan (2015) and Scinto (2014). A few students are keen to jump right into the experience, while most others benefit from the rational persuasion afforded by these readings. At the beginning of the class I play a ten-minute TEDx Talk by improviser and improv teacher Dave Morris (2011), in which he provides his key principles of improv, including:

1. Yes, And: Accepting what others offer and contributing your own idea

2. Listening: Be fully open to what others say, to the point of being willing to change your mind

3. Play: Engage in the challenge with presence and enjoyment

4. Let yourself fail: We all fail all the time, and failing at something doesn't define you as a failure

5. Abide by the rules: Recognizing the constraints of the context liberates creativity within those confines

6. Relax and have fun: Bring a positive attitude

Playing this TED talk serves two purposes. First, Morris is funny, so it lightens the mood in the classroom. Second, he nicely coalesces the literature on improv into a simple set of principles, thereby giving students a common starting point.

At this point in the class, I hand over the floor to members of the university's student improv club. Partnering with the student improv club is the critical key to success of this workshop. The members of the improv club are familiar faces and, since many of them only began improv during their college career, they have a fresh understanding of the trepidations students may experience. As Crossan (1998) notes, there is a great benefit to having professional improvisers lead non-improvisers through improv experiences. Indeed, both Huffaker and West (2005) and Shivarajan and Andrews (2019) both describe classroom improv experiences that were co-facilitated by professional improvisers. I did, in fact, explore bringing in trainers who specialize in teaching improv to business leaders, only to learn that it would cost approximately $\$ 2,000$. While this would be money well spent for a corporation, it was out of reach for a business school faculty member. The only "cost" of the student improv club members is permitting them a couple of minutes to advertise 
upcoming improv shows on campus.

Almost every college or university has a student improv club. Clubs are typically led by juniors or seniors who have a few years of experience, and over that time the students gain expertise in leading exercises and onboarding new members unfamiliar with improv. At the start of every semester, I send an email to the improv club's campus email address and arrange for 2-3 members to come to class and lead the workshop.

The format of the student-led portion of the workshop entails a series of improv "games," each followed by a debriefing focused on translating the experience to course concepts, and a global debriefing of takeaways at the end of the class. The exercises are ones the improv club uses in their weekly practices and pre-show warmups. Following I describe the typical exercises and the leadership lessons students report taking away from them; readers considering using this approach may find their campus improv club uses many of the same exercises and perhaps a few that are different. There are typically 30 students in my leadership classes, and some of the following exercises are suitable for the entire class, while others work best if I take advantage of the multiple improv club facilitators and break the class into smaller groups. For all exercises, the student facilitators describe the rules of the game and then offer an example before proceeding.

Fail ball. In this warmup game, the entire class forms a circle in the classroom. The objective is to pass an imaginary ball around the circle, with each receiver making an effort to catch the "ball"-only to fail and drop it. With each drop, the entire class erupts in applause, cheering the receiver's effort. The failed receiver then passes the ball to someone new, until everyone has attempted-and failed-to catch the imaginary ball.

When asked, "How does Fail ball relate to our study of leadership?" students tend to respond with comments like, "It reminds us we don't have to be perfect to put ourselves out there as leaders," and "It's important to recognize how others are making an effort, even if we're not happy with the results." The lessons relate back to previous course content regarding self-awareness and perspective-taking.

Pass the face. This second warmup exercise is a variant of the classic children's game of "telephone." Rather than a message being passed along, though, participants pass the expression and gestures they received from one classmate onto another classmate. Students work in smaller circles for this exercise, with the number of groups determined by how many facilitators are present. The critical aspect is that the participant needs only to attend to the expression communicated by their immediate neighbor, not with anything that happened earlier.

When asked, "How does Pass the face relate to our study of leadership?" students share comments about the importance of being focused and present in the moment and about how important attending to body language is in the listening process. These insights relate to earlier course lessons on effective listening in leadership.

Planning a party. Done in pairs, the objective of this exercise is to practice embodying the "Yes, and" approach. Each pair starts by attempting to plan a party, with instructions for every idea to be met with the response of, "No!" from the other. For example, "I think we should have a giant chocolate cake," would be met with something like, "No, I don't like chocolate." After a minute of this version of planning, the facilitator calls a timeout and asks for examples of what the party will look like; since every idea was rejected, no pair ever has any plan.

In the second iteration, the response to every idea is, "Yes, but..." which indicates there's some merit in the original idea, but not enough to move forward with it as stated. After a minute of this version, the facilitator asks for examples of party plans, and students tend to have some vague, uninteresting plans that neither partner cares about. Finally, students are instructed to respond with, "Yes, and..." by taking the idea as offered and then advancing it with their own ideas. Invariably, when asked by the facilitators for examples, students share wild brainstorms about 
parties featuring famous DJs with jugglers and ponies.

When asked, "How does Planning a party relate to our study of leadership?" students reliably share very rich insights. Some typical debriefing comments include: "This reminds me how important it is to be open when generating ideas since I typically dismiss others," "Saying, 'yes, but' is really just a different way of saying, 'no,' since it minimizes what the other person is saying," and "I really felt listened to when we did the 'yes, and' version." All these lessons pertain to course content on listening, perspective-taking, and collaborating.

Same word. This exercise challenges students' ability to think on their feet and try to find a mutual solution with someone else. Students are broken into as many groups as there are facilitators, and then stand in a circle. They start by having two students shout out the first random word they think of, such as "dog" and "hat." Going around the circle, adjacent students pause for a moment, and then at the count of three, they try to guess what word connects the two starter words; they might take "dog" and "hat" as starters and one say, "fluffy" while the other says, "warm." The next two students use "fluffy" and "warm" as input and guess what word they have in common-such as, "quilt." The round continues until the same word is said, which typically takes a couple of turns around the circle.

When asked, "How does Same word relate to our study of leadership?" the typical student responses are along the lines of, "This is all about trying to get outside your own head and take the perspective of someone else, which is what leaders should do all the time." As with previous exercises, this exercise directly relates to the course concepts of self-awareness, perspective-taking, collaboration, and taking risks.

Happily ever after. In this exercise, the whole class collaborates to tell a fairy-tale style story about a random topic. As students stand in a large circle, a facilitator selects someone to begin the story ("Once upon a time...") and then points to the next random student who is on the spot to continue the story. Sometimes the storyteller switches after a few sentences and sometimes it's in mid-sentence, after only a few words. Everyone must, then, pay very close attention to both the arc of the story and to each individual storytelling student, since they might be called on to pick up the sentence or thought midstream.

When asked, "How does Happily ever after relate to our study of leadership?" the student comments are invariably about how critical it is to listen with their whole attention and to speak generatively-that is, to use their speaking turn to open the floor to new ideas for others to pick up on. Many students have also noted the need to discard thoughts that have gone by the wayside and move where the group has moved; this insight, they say, is especially instructive in group meetings. These lessons relate to core course leadership concepts such as self-awareness, creativity, collaboration, and listening.

Dr. Know-it-All. In this final exercise, three or four student volunteers sit in the front of the room, collectively forming an entity who is a world-class expert at a topic randomly selected from the class. Students in the audience ask Dr. Know-it-All a question based on their subject of expertise (say, cars), and the members of Dr. Know-it-All respond to the question, one word at a time. If asked, for example, to explain how the internal combustion engine works, Dr. Knowit-All might say, "Based... on... my... understanding... of... engines..." until the sentence is complete. There may be time for two or three rounds of Know-it-Alls, with each group answering three or four questions from the class audience.

When asked, "How does Dr. Know-it-All relate to our study of leadership?" the students typically highlight the importance of flexibility, listening, and trying to make others look good. They also mention the importance of subjugating personal interests to those of the group: "I thought our sentence was going one way, but by the time it was my turn again, it had gone somewhere else. This reminds me of the importance of supporting the group's interests as a leader." As have other exercises, Dr. Know-it-All relates to course concepts such as self-awareness, 
Before ending the class session, I invite students to share their key take-aways that cut across all of the improv exercises. Their responses largely mirror what the literature argues to be the virtue of engaging in improvisation exercises: learning to be present, to listen, to offer their thoughts without reservation, to collaborate, to be creative, and to recognize that the serious work of leadership can still be fun.

\section{Effectiveness of the Improv Workshop}

After the first couple of times conducting the student-led improv workshop in my undergraduate leadership class, I began to see a pattern in end-ofsemester course evaluations, where many students would comment on how the improv session was one of the most challenging and rewarding parts of the class. Recently, as part of my routine solicitation of feedback from students, I began using a questionnaire to ask for anonymous feedback from students about the improv workshop following the end of the semester. Thus far, I have sent the questionnaire to 183 students over the past five semesters, with 85 anonymous responses $(46.4 \%$ response rate). The questionnaire included quantitative and qualitative components. Quantitatively, I asked four questions regarding the degree to which students felt the exercises helped them develop skills (listening, public speaking, creativity, and collaboration), four questions regarding the overall experience (did they enjoy it, have fun, wish to do it again, and would they recommend to a friend), if they were anxious before class about the thought of participating in the games, and if they felt more comfortable participating in class following the exercises. Responses used a 5-point Likert scale, where 1 indicated strongly disagree and 5 indicated strongly agree. The qualitative questions asked what their key lessons were and what recommendations they would offer to improve the experience.

Factor analysis indicated the four skills-based questions hung together as one factor and the four overall experience questions hung together as another. I therefore combined these questions into scales, which had high Cronbach alphas (skills $a=0.83$ and overall experience $a=0.86$ ). There were strong and statistically significant correlations among all of the perceptual indicators except for the degree to which they felt anxious about participating in the exercises beforehand; notably, this item was unrelated to any other item in the questionnaire. Table 1 displays descriptive statistics and correlations among items in the questionnaire.

Table 1.

Descriptive statistics and correlations of student responses to perceptual items.

\begin{tabular}{|l|l|l|l|l|l|}
\hline Item & Mean & S.D. & 1. & 2. & 3. \\
\hline 1. Anxious before & 3.51 & 1.25 & & & \\
\hline 2. Developed skills scale & 16.61 & 2.77 & .07 & & \\
\hline 3. Overall experience scale & 18.47 & 2.35 & .04 & $.66^{\star \star \star}$ & \\
\hline 4. More comfort participating & 3.88 & 1.04 & .08 & $.59^{\star \star \star}$ & $.52^{\star \star \star}$ \\
\hline
\end{tabular}

*** $\mathrm{p}<0.001$

$\mathrm{N}=85$

The quantitative results show the students felt the improv workshop helped them grow their leadership skills of listening, public speaking, creativity, and collaboration; reported having a good experience (including enjoying it, having fun, wishing to do it again, and saying they would recommend it to a friend); and indicated, on average, they felt more comfortable participating in class in the weeks following the improv workshop. This last point fits with my own sense of the class; following the improv workshop, I routinely see students who hadn't previously been very vocal in class discussions now much more eager to speak up and contribute. 
listening, collaboration, and creativity.

Students reported, on average, a slight amount of anxiety at the thought of participating in the exercises in front of their classmates. The relatively large standard deviation in the item indicated variation across the class in this item; about $21 \%$ of the students indicated they were not anxious (either strongly disagreeing or disagreeing with the item) and about 58\% said they were anxious (either strongly agreeing or agreeing with the item). Notably, the degree of anxiety before the exercises was not correlated with any other variable, so it had no effect on the students' experiences one way or another.

The qualitative data support the quantitative findings. Seventy-seven students responded to the open-ended question, "What were the key leadership lessons you learned from the improv workshop," and the most common response was about using a "yes, and" mindset (shared by $23 \%$ of the respondents). For example, one student wrote, "The major takeaway for me was the 'Yes, And' mentality. Not shooting down others' contributions and keeping the ball rolling in creative and collaborative discussions is important for a leader and his/her relationship with his/her team." Other common lessons shared included the importance of listening (18\%), being comfortable being uncomfortable (14\%), and being creative (9\%). Regarding listening, one student wrote the key lesson as, "Building conversations with constructive feedback rather than shooting ideas down. Truly listen and articulate your point of view in collaboration with the other person's idea and how they can work better together."

Other students captured their key lessons as, "Improv is leading-every day, leaders face unanticipated situations and so they must be quick on their feet to adapt themselves to the situation at-hand." And, "Honestly I was anxious going into it, but it is one class that I will remember long after college. It was so much fun and it was nice to just laugh and enjoy myself, but still learn things. It was really effective to do the Yes, And exercise." Finally, "You get more accomplished by saying 'yes, and' then (sic) you do saying 'yes, but' or 'no.' Also sometimes you need to let things go or let someone else take the moment. There is nothing wrong with being the set-up man. Without the set-up, the person cannot make the move."

I also asked what changes students would recommend to improve the improv workshop, and fifty-one students responded. Of those respondents, $27 \%$ said they would recommend keeping the workshop as it is and the same percentage said they would recommend making changes to give everyone as much practice as possible (such as using as many small group activities as possible). For example, one student wrote, "Easier ability for everyone to do an activity. I was too shy to raise my hand so if you pulled names out a hat people could participate. They could say no if they really did not want to do it." On the other hand, another student wrote, "Maybe put people less on the spot to participate because I know some of my friends didn't like feeling like they had to participate." The last common suggestion (from about $10 \%$ of the respondents) was to try to make the exercises more "realistic" or to reinforce an improv approach by practicing with other subjects later in the semester.

Overall, these data indicate support for the use of the improv workshop to develop leadership skills, while also indicating possible changes.

\section{Conclusion and Recommendations}

In environments marked by volatility, uncertainty, complexity, and ambiguity, leaders need to be equipped with skills to face novel challenges. These include self-awareness, listening, speaking, and collaborating skills. The improv workshop I have described provides a fun and challenging way to reinforce these skills in an undergraduate leadership course. Furthermore, the workshop works to develop a sense of psychological safety and community in the classroom that facilitates subsequent course lessons. The quantitative and qualitative data I have shared indicate students agree.

The critical innovation of my approach is to partner 
with an on-campus student improv club. For someone like me, who had no previous experience with improv, partnering with the improv club significantly lowered the barrier of entry and helped me overcome my own resistance to change my pedagogical toolkit (Oberg \& Andenoro, 2019).

As successful as this workshop is, there are limitations and ways to improve it. As many instructors do, I spend a great deal of effort to build trust and psychological safety from the first day of class (Oberg \& Andenoro, 2019). Instructors who have not intentionally worked to build psychological safety before engaging in an improvisation workshop may need to go out of their way to make it safe for students to take the risk of engaging in the improv exercises. For example, after initially standing aside and having the workshop be driven by students as facilitators and participants, I now make it a point to participate; taking the risk myself invites students to do the same. My participation also reinforces my dual identity as both instructor and co-learner of leadership.

In line with the student suggestions in the qualitative data, I recommend that instructors give careful thought to how they balance inviting and/ or requiring students to participate in the improv exercises. Engaging in uncertain situations is difficult because we can't tell what is going to happen next, and this can be anxiety-provoking for students and mature leaders alike. I will be attending to my sense of psychological safety developed leading up to the improv workshop, and if it seems to be high, I will lean toward an opt-out approach rather than an optin approach.

Finally, as informed by the qualitative data, I recommend being very mindful about using an improvisational approach in course sessions following the improv workshop, as appropriate. I make it a point to role model saying, "yes, and" when facilitating class discussions to illustrate the collaborative power of building upon others' thoughts. When engaging in other course content-such as delivering developmental feedback, for example-an intentional improvisational mindset would benefit students to learn the power of listening to others and sharing their perspectives. 


\section{References}

April, K., Beall, C., \& Peters, K. (2015). Understanding leadership through the arts. Effective Executive, 18(4), 18-39.

Aylesworth, A. (2008). Improving case discussion with an improv mind-set. Journal of Marketing Education, 30, 106-115.

Barrett, F.J. (1998). Creativity and improvisation in jazz and organizations: Implications for organizational learning. Organization Science, 9, 605-622.

Chikeleze, M., Johnson, l., \& Gibson, T. (2018). Let's argue: Using debate to teach critical thinking and communication skills to future leaders. Journal of Leadership Education, 17(2), 123-137.

Christopoulos, T.P., Wilner, A., \& Bestetti, M.L.T. (2016). Experimental learning enhancing improvisation skills. The Learning Organization, 23, 415-428.

Colbry, S., Hurwitz, M., \& Adair, R. (2014). Collaboration theory. Journal of Leadership Education, 13(4), 63-75.

Crossan, M.M. (1998). Improvisation in action. Organization Science, 9, 593-599.

Fisher, C.M., \& Barrett, F.J. (2019). The experience of improvising in organizations: A creative process perspective. Academy of Management Perspective, 33, 148-162.

Flanagan, L. (2015). How improv can open up the mind to learning in the classroom and beyond. Retrieved from https://www.kqed.org/mindshift/39108/how-improv-can-open-up-the-mind-to-learning-in-theclassroom-and-beyond

Gagnon, S., Vough, H.C., \& Nickerson, R. (2012). Learning to lead, unscripted: Developing affiliative leadership through improvisational theatre. Human Resource Development Review, 11, 299-325.

Gerras, S.J. (Ed.). (2010). Strategic leadership primer (3rd ed.). Carlisle, PA: US Army War College.

Gibb, S. (2004). Arts-based training in management development: The use of improvisational theatre. Journal of Management Development, 23, 741-750.

Greenberg, E. (1995). Improv in the classroom: An experiential exercise. Journal of Management Education, $19,519-522$.

Guenthner, J.F., \& Moore, L.L. (2005). Role playing as a leadership development tool. Journal of Leadership Education, 4(2), 59-65.

Hadida, A.L., Tarvainen, W., \& Rose, J. (2015). Organizational improvisation: A consolidated review and framework. International Journal of Management Reviews, 17, 437-459.

Huffaker, J.S., \& West, E. (2005). Enhancing learning in the business classroom: An adventure with improv theater techniques. Journal of Management Education, 29, 852-869.

Kamoche, K., Cunha, M.P., \& Cuhna, J.V. (2003). Towards a theory of organizational improvisation: Looking beyond the jazz metaphor. Journal of Management Studies, 40, 2023-2051. 


\section{References}

Koppett, K. (2002). Business and the art of improvisation. The British Journal of Administrative Management, $33,26-27$.

Lewin, A.Y. (1998). Jazz improvisation as a metaphor for organization theory. Organization Science, 9, 539.

Lindsay, D.R., Hassan, A.M., \& Day, D.V. (2009). Leadership education and experience in the classroom: A case study. Journal of Leadership Education, 8(2), 32-40.

Morris, D. (2011, November 19). The way of improvisation [Video file]. Retrieved from https://www.youtube. com/watch?v=MUO-pWJOriQ

Moshavi, D. (2001)."Yes and...": Introducing improvisational theatre techniques to the management classroom. Journal of Management Education, 25, 437-449.

Newton, P.M. (2004). Leadership lessons from jazz improvisation. International Journal of Leadership in Education, 7, 83-99.

Oberg, M.G., \& Andenoro, A.C. (2019). Overcoming leadership learning barriers: A naturalistic examination for advancing undergraduate leadership development. Journal of Leadership Education, 18(3), 53-69.

Peplowski, K. (1998). The process of improvisation. Organization Science, 9, 560-561.

Ratten, V., \& Hodge, J. (2016). So much theory, so little practice: A literature review of workplace improvisation training. Industrial and Commercial Training, 48(3), 149-155.

Raymer, S.D., Dobbs, J., Kelley, C.P., \& Lindsay, D.R. (2018). Leadership education and development: Theory driven evolutions. Journal of Leadership Education, 17(2), 138-148.

Scinto, J. (2014). Why improv training is great business training. Retrieved from https://www.forbes.com/ sites/forbesleadershipforum/2014/06/27/why-improv-training-is-great-business-training/\#7c21a95c6bcb

Shivarajan, S., \& Andrews, R. (2019). Using improvisation to develop emotional intelligence. Management Teaching Review. Advance online publication. doi: 10.1177/2379298119882339

Tabak, F., \& Lebron, M. (2017). Learning by doing in leadership education: Experiencing followership and effective leadership communication through role-play. Journal of Leadership Education, 16(2), 199-212.

Tawadros, T. (2015). Developing the theater of leadership: An exploration of practice and the need for research. Advances in Developing Human Resources, 17(3), 337-347.

Vera, D., \& Crossan, M. (2005). Improvisation and innovative performance in teams. Organization Science, $16,203-224$.

Vera, D. \& Rodriguez-Lopez, A. (2007). Leading improvisation: Lessons from the American Revolution. Organizational Dynamics, 36(3), 303-319.

Weick, K.E. (1998). Improvising as a mindset for organizational analysis. Organization Science, 9, 543-555. 